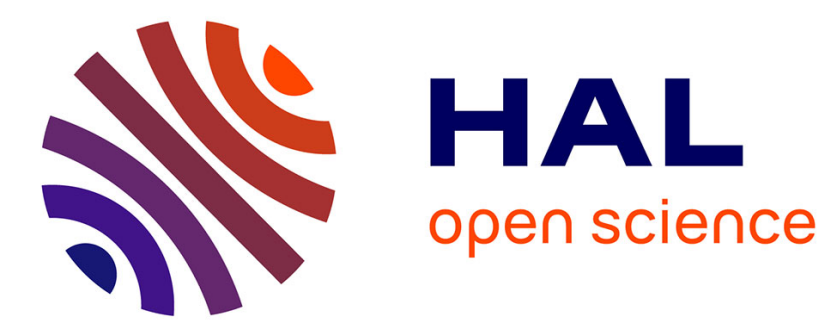

\title{
Small "F-gain" printed slot antenna for IR-UWB wireless sensor networks applications
}

Hamadache Zemmour, Antoine Diet, Geneviève Baudoin

\section{To cite this version:}

Hamadache Zemmour, Antoine Diet, Geneviève Baudoin. Small "F-gain" printed slot antenna for IR-UWB wireless sensor networks applications. EUMW 2014 (EUMC/EURAD), Oct 2014, Rome, Italy. pp.1675 - 1678, 10.1109/EuMC.2014.6986777 . hal-01104666

\section{HAL Id: hal-01104666 \\ https://hal-centralesupelec.archives-ouvertes.fr/hal-01104666}

Submitted on 18 Jan 2015

HAL is a multi-disciplinary open access archive for the deposit and dissemination of scientific research documents, whether they are published or not. The documents may come from teaching and research institutions in France or abroad, or from public or private research centers.
L'archive ouverte pluridisciplinaire HAL, est destinée au dépôt et à la diffusion de documents scientifiques de niveau recherche, publiés ou non, émanant des établissements d'enseignement et de recherche français ou étrangers, des laboratoires publics ou privés. 


\section{Small 'F-gain' Printed Slot Antenna for IR-UWB Wireless Sensors Network Applications}

\author{
Hamadache ZEMMOUR, Geneviève BAUDOIN \\ Université Paris-Est, ESYCOM (EA2552), ESIEE-Paris \\ 2 Bd Blaise Pascal, BP 99, Noisy le Grand, France \\ (hamadache.zemmour, genevieve.baudoin)@esiee.fr
}

\author{
Antoine DIET \\ L2S/DRE UMR 8506 - LGEP UMR 8507 \\ Plateau du Moulon, F-91192 Gif Sur Yvette, France \\ antoine.diet@u-psud.fr
}

\begin{abstract}
This work focuses on antennas for wireless IRUWB sensor network (WSN). A novel small $\left(<\mathbf{5} \mathbf{c m}^{2}\right)$ planar monopole ultra-wideband (UWB) micro-strip fed antenna is presented. WSN are difficult cases for communications, implying the antenna to be adapted to the channel. The first consideration is the path loss compensation, especially for Ultra Wide Band signals. The characterization of the antenna is done in both frequency and time domain and shows a return loss $<10 \mathrm{~d} B$ from 4,2 to $12.4 \mathrm{GHz}$ (including the $6-8,5 \mathrm{GHz}$ ), fidelity factors of more than $90 \%$ and pulse width stretch ratio lower than $6 \%$. The antenna transfer function is analyzed. It increases with frequency, providing a quasi-constant transmission channel transfer function (antenna\&channel). Return loss and radiation pattern are depicted. The time domain analysis, via Fidelity factor and pulse width Stretch Ratio, confirms its non-distortion behavior. The designed antenna has a small size of $20 \times 20 \times 0.8 \mathrm{~mm}^{3}$, and an omnidirectional radiation pattern over the frequency band considered.
\end{abstract}

Keywords-impulse radio ultrawideband (IR-UWB); wireless sensor network (WSN); UWB printed slot antenna; antenna transfer function; fidelity.

\section{ANTENNA FOR IR-UWB}

In the last decade, ultra-wideband technology (UWB) has attracted a huge interest on communication, radar, localization systems and wireless sensors network. Impulse Radio UWB (IR-UWB) has the potential advantage of spread spectrum immunity and low power consumption. Consequently, this communication technology is highly focusing on small low cost antennas. The Federal Communication Commission (FCC) allocated the frequency band 3.1 to $10.6 \mathrm{GHz}$ for the UWB in 2002[1]. On February 2007, the commission of the European Communities released a decision on using $(6-8.5 \mathrm{GHz})$ radio spectrum band for UWB technology [2]. Recently, UWB transponders for Wireless Sensors Networks (WSN) applications have been proposed [3][4]. The UWB WSN system requires the conception of UWB transmitter and receiver with dedicated antennas. The main requirement for such antennas are a small size, omnidirectional pattern, low cost, a huge operational bandwidth and non-dispersive behavior [5][6].

Furthermore, the channel transfer function is decreasing with increasing frequency [7][8][9][10], depending on the path loss attenuation factor. Therefore, if the antenna transfer function increases with frequency (for example "F-gain"[10]), it may compensate this dependency and limits the signal distortion (fidelity increased) which allows getting better transmission [5][9][11][12]

The time domain analysis completes the frequency domain results by studying the effect of the antenna on the transmitted signal. For investigating the time domain transmission of the antenna, a transmitted signal waveform has to be defined. This waveform can be theoretically (all frequencies of the passband) or based on the technology possibilities (Gaussian filtered pulse) for better accuracy with possible transmitter realization. Two criteria of performance are evaluated: the Fidelity factor $(F)$ and the pulse width Stretch Ratio $(S R)$ [8].

In this paper, a novel small "F-gain" UWB monopole antenna for IR-UWB WSN operating in the European regulated frequency range $(6-8.5 \mathrm{GHz})$ is presented. The design is based on modified rectangular shaped patch, with a $50 \Omega$ micro-strip feed line, and a square ground plane with a wide ellipse shaped slot. Slots and parasitic element are added to improve the antenna performances and customize the frequency dependence of the gain. The performances of the presented antenna fulfill the UWB WSN antenna requirements.

\section{ANTENNA DESIGN AND CHARACTERISTICS}

The geometry of the studied antenna and the realized prototype are shown in Fig.1. It is based on a modified rectangular radiator, with two half elliptical shapes at its horizontal edges and a central H-slot, introducing some design degrees of freedom. The radiator patch is fed by a $50 \Omega$ microstrip line. The ground plane of the antenna consists of a rectangular patch with a wide slot, similar in its shape to the radiator, a small T-slot and an elliptical parasitic patch. The slots and the parasitic element are added to improve and satisfy the performance requirements of the small sized monopole antenna [6][9]. Signal transmission is achieved by means of an SMA connector welded to the micro-strip feed line and ground.

The performances of the antenna depend on its different geometric parameters. At low frequencies, the operating of the antenna critically depends on its lateral length. This length fixes the lower edge of the operating bandwidth. Then, an optimization approach based on the tradeoff between 
miniaturization and operating bandwidth is considered. The simulation was performed using CST Microwave Studio. The antenna prototype is designed on low cost substrate with $0.8 \mathrm{~mm}$ thickness and relative dielectric constant 3.3. The realized antenna is firstly considered for sensor networks applications, working on the European UWB frequency standard (6-8.5GHz).

The performance of the studied antenna depends on its geometry. A mandatory parametric study was done to obtain the optimum structure, fulfilling the system requirements. Optimal dimensions (listed in Fig.1.a) of the proposed antenna are given in TABLE I.

The simulated return loss of the antenna, shown in Fig.2, is less than $-10 \mathrm{~dB}$ over a wide frequency band $(4.2-12.4 \mathrm{GHz})$, with nearly linear phase (with a slope of $-49^{\circ} / \mathrm{GHz}$ ) which minimizes the dispersion of the transmitted pulse signal.

The antenna radiation patterns in the E-plane and H-plane, at 5, 7.25 and $10 \mathrm{GHz}$, are depicted in Fig.3. These results clearly expose the omnidirectional behavior of the antenna over the operational bandwidth.

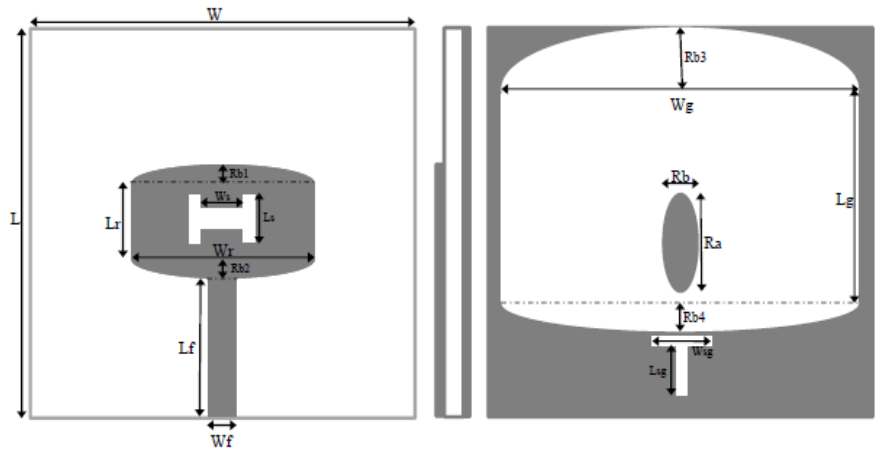

$-a-$

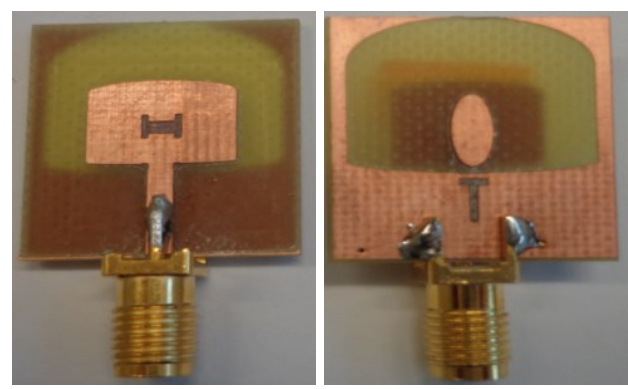

$-b-$

Fig. 1. The proposed $2 \times 2 \mathrm{~cm}^{2}$ UWB antenna: a-geometry, b-prototype.

TABLE I. OPTIMIZED ANTENNA PARAMETERS (mm)

\begin{tabular}{|c|c|c|c|c|c|c|c|c|}
\hline L & W & Lf & Wf & Lr & Wr & Ls & Ws & Rb1 \\
\hline 20 & 20 & 7.65 & 1.85 & 6 & 11 & 2 & 2 & 1 \\
\hline Rb2 & Rb3 & Rb4 & Ra & Rb & Lg & Wg & Lsg & Wsg \\
\hline 0.2 & 4 & 1 & 3 & 1.5 & 8 & 17.8 & 3 & 2 \\
\hline
\end{tabular}

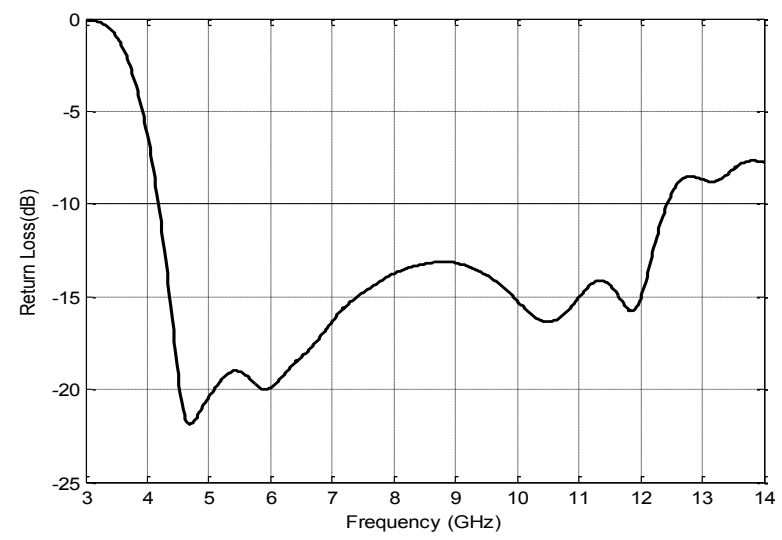

Fig. 2. Return loss of the proposed antenna.
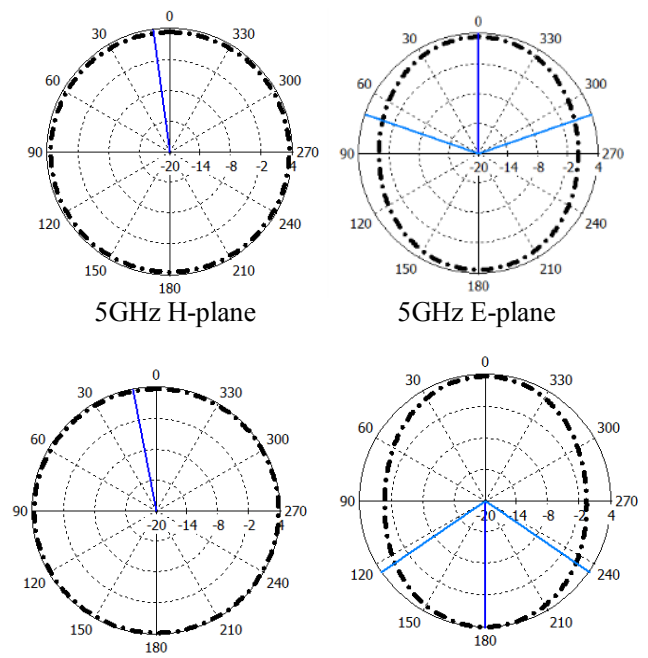

7.25GHz H-plane

7.25GHz E-plane

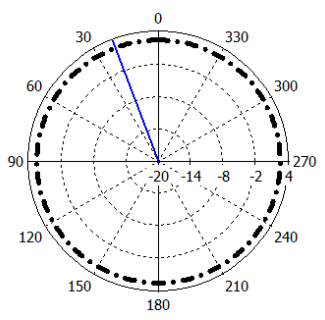

$10 \mathrm{GHz} \mathrm{H}-$ plane

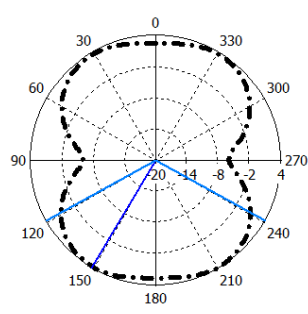

$10 \mathrm{GHz}$ E-plane

Fig.3. E-plane and H-plane radiation patterns at 5,7.25 and 10GHz.

\section{TRANSFER FUNCTION ANALYSIS}

To achieve this frequency domain analysis, two identical antennas were considered in free space environment. The transmitting antenna (Port 1) and receiving antenna (Port 2) were located in the same plane, at a distance (d) of $30 \mathrm{~cm}$ inLOS (Line Of Sight). The receiving antenna was rotated around its symmetrical axis, with an angular step of $90^{\circ}$, for each $\mathrm{S}_{21}$ capture, while the transmitting antenna was kept fixed. The rotation angle covers the whole azimuthal plane (H-plane), and $0^{\circ}$ is the angle where both antennas are pointed to each other. 
The $\mathrm{S}_{21}$ results represent the transfer function of the system, composed by the two identical antennas and the ideal free space channel, in the azimuthal plane. The transfer function of the system $H_{s}(f)$ can be written as [5]

$$
H_{s}(f)=H_{t}(f, \theta, \varphi) H_{c}(f, d) H_{r}(f, \theta, \varphi)
$$

where

$$
H_{c}(f, d)=\frac{c}{4 \pi f d} e^{-j \frac{2 \pi f}{c} d}
$$

is the free space transfer function for electric field representation.. $H_{t}(f, \theta, \varphi)$ and $H_{r}(f, \theta, \varphi)$ are the transmitting and receiving antennas transfer functions toward $\theta$ and $\varphi$ directions.

In this work, transmitting and receiving antennas are identical, then their transfer functions can be given as[5]

$$
H_{t}(f, \theta, \varphi)=H_{r}(f, \theta, \varphi)=\sqrt{\frac{H_{s}(f)}{H_{c}(f, d)}}
$$

The results shown in Fig.4 represent the transfer function of the system (transmitting antenna - free space channel receiving antenna), versus rotation angle $\theta$. One can notice the flat form of the result around the band of interest $(6-8.5 \mathrm{GHz})$, especially, with a fluctuation of about $2 \mathrm{~dB}$, which causes similar attenuation on all the frequency bandwidth of the signal, and then limits the distortion effect of the transmitted pulses.

Considering (3), the antenna transfer function is processed and represented in Fig.5. We can note the increasing transfer function of the antenna on the band of interest, which allows compensating for the frequency dependency, caused by the free space transfer function (which decreases with increasing of frequency). Thus, this performance permits to get a flat channel transfer function.

In the case of more important path losses, the design of the antenna can be adapted by properly varying the slots and parasitic element dimensions, in the idea to improve the antenna gain and then to overcome the propagation degradation.

\section{TIME DOMAIN ANALYSIS}

\section{A. Transmitted Pulse}

Time domain analysis consists in studying the effect of the antennas (emission and reception) combined with the channel on the transmitted signal. Then, a comparison is done between transmitted signal $v_{t}(t)$ and received signal $v_{r}(t)$ at each electrical port of the antenna, to evaluate the undergone alteration. The transmitted impulse signal, $v_{t}(t)$, used to achieve this analysis consists on the frequency-translated Gaussian voltage waveform, given by:

$$
v_{t}(t)=k e^{-\alpha t^{2}} \cos \left(2 \pi f_{c} t\right)
$$

where $k$ is the maximum amplitude, $\alpha$ is a parameter determining the width of the signal in the time domain, and $f_{c}$ is the center frequency. The transmitted and received impulse signals are illustrated in Fig.6.

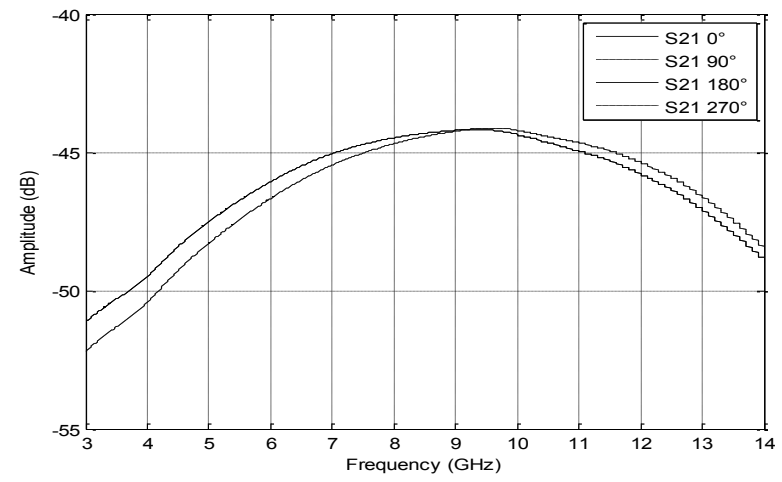

Fig. 4. Magnitude of S21 at $0^{\circ}, 90^{\circ}, 180^{\circ}$ and $270^{\circ}$ directions.

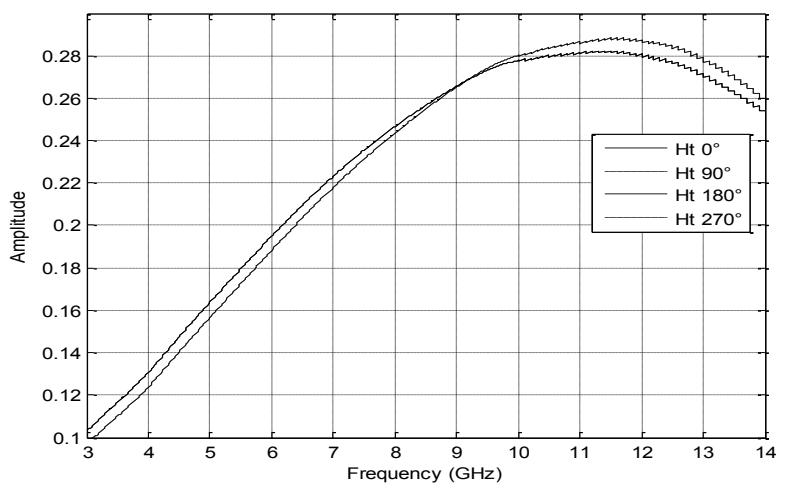

Fig. 5. Magnitude of antenna transfer function from (3).
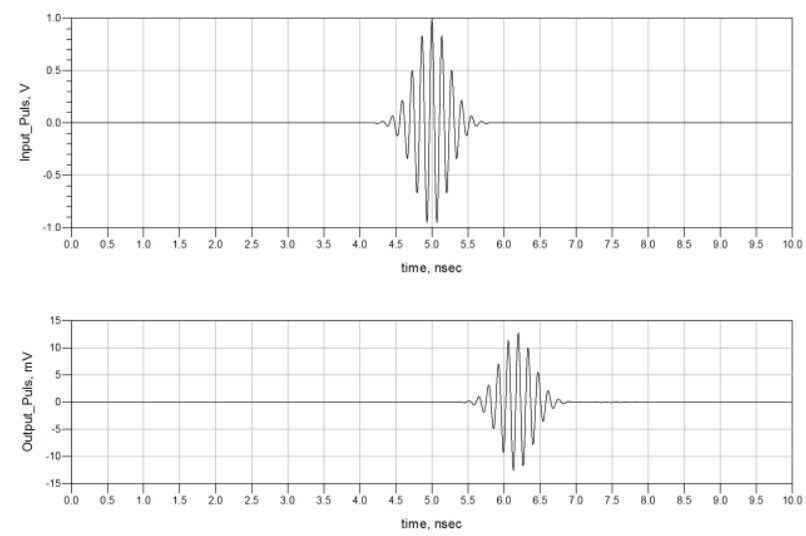

Fig. 6. UWB signal (a) transmitted impulse, (b) received impulse.

\section{B. Fidelity Factor F}

The received impulse signal is distorted by the UWB antennas. To measure the degree of distortion, the fidelity factor $(F)$ is calculated [8]. It compares the transmitted and received impulse signals by mean of a correlation calculation. The antenna presents the best performances when the fidelity factor is close to 1 , and the worst case is $F=0$. Thus, the fidelity factor is given by: 


$$
F=\max \frac{\left|R v_{r} v_{t}(\tau)\right|}{\sqrt{R v_{t} v_{t}(0) R v_{r} v_{r}(0)}}
$$

where $R v_{r} v_{t}(\tau)$ is the cross correlation of the transmitted and received signals, and $R v_{x} v_{x}(0)$ is the autocorrelation of the corresponding signal.

For the studied antenna, fidelity factor $(F)$ versus rotation angle $\theta$ is given in TABLE 2. From TABLE.2, the miniature printed slot antenna presents a high fidelity factor (more than $90 \%$ ) over the main angles directions.

\section{Pulse Width Stretch Ratio SR}

The temporal width of the transmitted impulse signal is of great importance: the smallest the pulse width, the higher the transmission data rate. However, UWB antenna causes width stretching to the transmitted waveform, which constrains the use of longer inter-pulse gaps that means decreasing of transmission rate. An evaluation of the pulse width stretching is necessary to determine the performance of the antenna.

The parameter which allows assessing this phenomenon is the pulse width Stretch Ratio $(S R)$ [8]. The best performance of antenna is for $S R$ close to 1, and it worsens with its increasing. The calculation of $S R$ is based on comparing energy distribution between the transmitted and received pulses. The pulse width can be defined as the width of the time window containing a $90 \%$ of the total energy. For a signal $v_{x}(t)$, let the normalized cumulative energy function $E_{v}(t)$ be defined by

$$
E_{v}(t)=\frac{\int_{-\infty}^{t}\left|v_{x}(\tau)\right|^{2} d \tau}{\int_{-\infty}^{\infty}\left|v_{x}(\tau)\right|^{2} d \tau}
$$

Then, the pulse width $W(v)$ for $90 \%$ energy capture is given by

$$
W(v)=E_{v}^{-1}(0.95)-E_{v}^{-1}(0.05)
$$

The pulse width stretch ratio $S R$ can be defined by the ratio of the width of the received waveform to the width of the transmitted waveform, as

$$
S R=\frac{W\left(v_{r}\right)}{W\left(v_{t}\right)}
$$

For the studied antenna, results of pulse width Stretch Ratio $(S R)$ versus rotation angle $\theta$ are given in TABLE 3. From TABLE.3, the $S R$ of the proposed antenna is close to 1 over the main angles directions in the azimuth plane, which means good performance of the antenna and non-dispersive behavior.

TABLE 2. FIDELITY FACTOR OF THE ANTENNA.

\begin{tabular}{|c|c|c|c|c|}
\hline$\theta$ & $0^{\circ}$ & $90^{\circ}$ & $180^{\circ}$ & $270^{\circ}$ \\
\hline$F$ & 0.9918 & 0.9728 & 0.9915 & 0.9726 \\
\hline
\end{tabular}

TABLE 3. PULSE WIDTH STRETCH RATIO.

\begin{tabular}{|c|c|c|c|c|}
\hline$\theta$ & $0^{\circ}$ & $90^{\circ}$ & $180^{\circ}$ & $270^{\circ}$ \\
\hline$S R$ & 1.037 & 1.057 & 1.039 & 1.058 \\
\hline
\end{tabular}

\section{CONCLUSION}

In this paper, a novel small and compact planar monopole UWB antenna was presented. The proposed antenna has a huge bandwidth from $4.2 \mathrm{GHz}$ to $12.4 \mathrm{GHz}$ and an omnidirectional radiation pattern from 5 to $10 \mathrm{GHz}$ in $\mathrm{E}$ and $\mathrm{H}$ planes. Its transfer function is increasing with frequency on the European UWB regulatory band and then compensates for the effect of channel propagation path loss attenuation. The Fidelity factor and Stretch Ratio of the antenna are respectively higher than $90 \%$ and lower than 5\%, in the H-plane, which confirm its nondistortion behavior.

With such dimensions, $20 \times 20 \times 0.8 \mathrm{~mm}^{3}$, and presenting the aforementioned performances, the proposed antenna is suitable for IR-UWB WSN applications. The perspectives of our work are to customize this type of antenna in different propagation channel with higher path loss and non-LOS cases.

\section{REFERENCES}

[1] Federal Communications Commission, "Revision of part 15 of the commission's rules regarding ultra-wideband transmission systems," First Report and Order, ET Docket 98-153, FCC 02-48, April 2002.

[2] W. Hirt, The european UWB radio regulatory and standards framework: Overview and implications, [ in Proc. IEEE Int. Conf. Ultra-Wideband, Singapore, 2007, pp. 733-738.

[3] M. Baghaei-Nejad, Z. Zou, H. Tenhunen, and L.-R. Zheng, "A novel passive tag with asymmetric wireless link for rfid and wsn applications," in Circuits and Systems, 2007. ISCAS 2007. IEEE International Symposium on, may 2007, pp. $1593-1596$.

[4] A. Toccafondi, D. Zampilli, C. Della Giovampaola, and V. Tesi, "Lowpower uwb transmitter for rfid transponder applications," in to appear on RFID-Technologies and Applications (RFID-TA), 2012 IEEE International Conference on, vol. 1, November 2012.

[5] S. Promwong, W. Hachitani, J. Takada, "Free space link budget evaluation of IR-UWB systems," Ultra Wideband Systems, 2004. International Workshop on Ultrawideband Systems and Technologies 2004 UWBST\& IWUWBS, pp.312- 316, 18-21 May, 2004.

[6] M. A. Peyrot-Solis and al. "State of the Art in UWB Antennas" $2^{\text {nd }}$ International Conf. on Electrical and Electronics Engineering (ICEEE), Mexico, Sept. 2005.

[7] M. Ghavami, L. Michael and R. Khono. "UWB signals and systems in communications engineering" Wiley 2004.

[8] Do-Hoon Kwon, "Effect of antenna gain and group delay variations on pulse-preserving capabilities of ultrawideband antennas," IEEE Transactions on Antennas and Propagation, vol.54, no.8, pp.2208-2215, Aug.,2006.

[9] H. Schantz. "The Art and Science of UltraWideBand Antennas" Artech House, 2005.

[10] A. Diet, N. Ribière-Tharaud. An "F-gain" antenna for UWB-RFID. Progress In Electromagnetics Research, PIER C, ISSN: 1937-8718, $\mathrm{N}^{\circ} 20$, pp. 111-123, 2011

[11] D. Panaitopol, J. Fiorina, A. Diet, N. Ribière-Tharaud. A New Criterion to Jointly Design the Antenna and Optimize the Communication Capacity in IR-UWB. PHY 6.1, IEEE Wireless Communications and Networking Conference WCNC, Budapest, may 2009, Hungary

[12] R. Scholtz and al. "Ultra-Wideband Radio" EURASIP Journal on Applied Signal Processing, March 2005, pp 252-272. 